output node), or that the training set should include over 30000 cases.

The aim in training a classification ANN is to extract features from the training data that characterise the classes of interest. Since Zou et al's ANN has well over 15000 path options for the training set of 60 cases, the feature extraction properties of the ANN were redundant. The ANN was simply required to represent each training case in learning space. Classification of the test data would have proceeded by finding the closest match among the training data representations and adopting this diagnosis. Zou et als approach has, therefore, probably created a pattern matching system rather than a true ANN classification system. As such, it achieved a satisfactory result, but would be expected to be less successful when more diagnostic groups are added and the classification task is more complex.

ANNs have considerable promise in the classification of psychiatric disorders (Galletly et al, 1996). However, an ANN is not merely a black box. Attention must be given to the choice of appropriate architecture, input data, training and test data sets, classification thresholds and initial weights, all of which appear to be either less than optimal or unspecified in Zou et al's paper.

Galletly, C., Clark, C. \& McFarlane, A. (1996) Artificial neural networks: A prospective tool for the analysis of psychiatric disorders. Journal of Psychiatry and Neuroscience, 21, 239-247.

Zou, Y., SHEn, Y., SHu, L., et al (1996) Artificial neural network to assist psychiatric diagnosis. British Journal of Psychiatry, 169, 64-67.

C. A. Galletly C. R. Clark

Cognitive Neuroscience Laboratory and School of Psychology

Flinders University of South Australia

GPO Box 2100

Adelaide, SA 5001

A. C. McFarlane

Department of Rehabilitation and Community

Psychiatry

University of Adelaide

South Australia

\section{Lithium and ECT in combination}

SIR: We read with interest the article by Jha et al (1996). The clinical implication suggested by the authors, "The combination of ECT and lithium may be justified in selected cases" needs to be viewed with caution. There are some reports to suggest increased risk of neurotoxicity associated with ECT and lithium in combination (Small et al, 1980; El-Mallakh, 1988). Potential risk of prolongation of depolarising muscle relaxant effects by lithium is possible (Hill et al, 1976). In any case, there are no confirmed trials showing therapeutic advantage of ECT and lithium in combination over ECT sans lithium.

It is therefore clinically prudent to withhold lithium during ECT. Lithium may be restarted, if indicated, after completion of a course of ECT. In our experience, such a strategy has not resulted in any symptom relapse during the period before therapeutic levels are achieved.

El-Mallakh, R. S. (1988) Complications of concurrent lithium and electroconvulsive therapy: $A$ review of clinical material and theoretical considerations. Biological Psychiatry, 23, 595-601.

Hill, G. E., Wong, K. G. \& Hodges, M. R. (1976) Potentiation of succinylcholine neuromuscular blockade by lithium carbonate. Anesthesiology, 44, 439-441.

Jha, A. K., Stein, G. S. \& Fenwick, P. (1996) Negative interaction between lithium and electroconvulsive therapy - A case-control study. British Journal of Psychiatry, 168, 241-243.

Small, J. G., Kerlams, J. J., Milstein, V., et al (1980) Complications with electroconvulsive treatment combined with lithium. Biological Psychiatry. 15, 103-112.

B. N. GangadhaR

Department of Psychiatry

N. JANAKIRAMAIAH

National Institute of Mental Health and

Neurosciences

Bangalore 560029

India

\section{False memory syndrome}

SIR: I wish to clarify a comment about the False Memory Syndrome Foundation made by Brewin in his editorial (1996). He states:

"Recently, however, doubt has been cast on the process whereby forgotten memories of child sexual abuse appear to be recovered within therapy, and it has been suggested that many if not all of these memories are the product of inappropriate therapeutic suggestion. This suggestion has been promulgated in particular by the False Memory Syndrome Foundation in the US. ..

The False Memory Syndrome Foundation has no way of knowing whether or not "many" memories recovered in therapy are the product of inappropriate suggestion. Therapy sessions are confidential. There does, however, seem to be ample evidence that some memories recovered in therapy may be false. There is also evidence that some therapists practice techniques that carry a high risk of suggestion. Research by Poole et al (1994) indicates that 
$25 \%$ of $\mathrm{PhD}$ psychologists use techniques that increase the risk of memory suggestion.

We have noted that there is a distinction between the claims of recovery of a memory of a single event and the claims of recovery of many memories of hundreds of events extending over long periods of many years. The reports that have been received by the False Memory Syndrome Foundation generally include claims that a person has recovered many memories of numerous events that took place over many years after total amnesia for all these events. Such claims represent a new kind of phenomenon. In 1989 Briere introduced a new mental mechanism that he said was only recently discovered and causes patients to become completely amnestic and suffer the "complete loss of childhood sexual abuse memories" (p. 49). Extraordinary claims deserve extraordinary evidence. Without such evidence, such claims must be taken with scepticism.

The position of the Foundation has always been that whether they are continuous or recovered, some memories are true, some a mixture of fact and fantasy and some are false. The problem is to know the difference.

BrIERE, J. (1989) Therapy for Adults Molested as Children: Beyond Survival. New York: Springer.

BREWIN, C. R. Scientific status of recovered memories. British Journal of Psychiatry, 169, 131-134.

Poole, D., et al (1994) Psychotherapy and the recovery of memories of childhood sexual abuse: US and British practitioners' opinions, practices, and experience. Journal of Consulting and Clinical Psychology, 63, 426-437.

FMS Foundation

P. FREYD,

Phildelphia, PA 19104

USA

Baclofen therapy for rigidity associated with Lewy body dementia

SIR: Lewy body dementia (LBD) often shows a marked sensitivity to neuroleptics (McKeith et al, 1992). Anticholinergic agents used to treat extrapyramidal side-effects of these drugs are often unsuccessful in LBD and can exacerbate confusion and psychosis. We report a case of LBD with severe extrapyramidal rigidity who responded well to treatment with baclofen, a $\gamma$-aminobutyric acid agonist.

Mrs T., a 90-year-old widow, was admitted with a two-year history of memory loss. Distressing visual hallucinations included "a baby monkey with a long tail". She had become disoriented and repeatedly and inappropriately telephoned her neighbours. Cognition was globally impaired (Mini Mental State Examination 13/30). Physical examination revealed only impaired visual acuity. Investigations were normal. Sulpiride (100 $\mathrm{mg}$ per day) was commenced but the patient soon became drowsy and showed marked stiffness and cogwheeling. She became immobile, uncommunicative and doubly incontinent. The sulpiride was stopped and a diagnosis of "probable dementia with Lewy bodies" was made (International Workshop on Dementia with Lewy Bodies, 1996, in press). Procyclidine was commenced and gradually increased to $10 \mathrm{mg}$ t.d.s. but rigidity steadily worsened. The patient was frightened, screaming at times, hardly ate and required intermittent intravenous hydration. Eleven weeks after stopping the sulpiride, baclofen was started and cautiously increased to $15 \mathrm{mg}$ t.d.s. while procyclidine was reduced and stopped. (Baclofen may itself exacerbate psychosis and confusion.)

Two weeks later Mrs T. was much more settled, with no signs of distress. Her affect was reactive, while verbal communication and oral input improved markedly. Stiffness gradually resolved and mobility improved. In another patient with LBD we have again found that baclofen was far more effective than procyclidine in reducing stiffness. Baclofen may therefore be useful in the treatment of rigidity associated with diffuse Lewy body dementia, and merits further evaluation. (Acknowledgement: Thanks to Rodney Walker for his advice.)

INTERNATIONAL WORKSHOP ON DEMENTIA WITH LEWY BODIES (1996) Consensus criteria for the clinical diagnosis of dementia with Lewy bodies. Neurology, in press.

McKeith, I. G., FaIrbairn, A., Perry, R., el al (1992) Neuroleptic sensitivity in patients with senile dementia of Lewy body type. British Medical Journal, 305, 673-678.

Department of Psychiatry

M. Moutoussis

Princes Alexandra Hospital

Harlow CM20 1QX

University College London Medical School

Middlesex Hospital

London WIN 8AA

\section{An atypical case of parasuicide or 'bradysuicide'}

SIR: The term parasuicide refers to a non-fatal deliberate act of self-injury or ingestion of substances in excess of normally used doses.

A 35-year-old kindergarten teacher, who had a past history of sedative overdose, became depressed upon her father's death and decided to end her life 